\title{
The origins of the mantle's carbon and the bulk carbon content of the Earth
}

\section{REBECCA A FISCHER ${ }^{1}$, LIZ COTTRELL ${ }^{2}$, ERIK H. HAURI $^{3}$, KANANI LEE ${ }^{4}$ AND MARION LE VOYER ${ }^{2}$}

${ }^{1}$ Harvard University

${ }^{2}$ Smithsonian Institution

${ }^{3}$ Carnegie Institution for Science

${ }^{4}$ Lawrence Livermore National Laboratory

Presenting Author: rebeccafischer@g.harvard.edu

Carbon in Earth's mantle influences melting and dynamics; significant carbon in the core would influence dynamics, thermal structure, and physical properties. However, the abundances and origins of carbon in deep Earth reservoirs are poorly constrained.

We performed experiments on carbon metal-silicate partitioning at 37-59 GPa and 4200-5200 K [1] (Figure 1). Carbon is $\sim 2$ orders of magnitude less siderophile at these conditions compared to previous results at more modest pressures and temperatures [e.g., 2-5].

Using a continuous core formation model for the Earth, we can match the mantle's carbon content (120 ppm [6]) and simultaneously reproduce the mantle's composition and core's light element abundance (Figure 2). It is therefore possible that Earth's mantle carbon originated from core formation, without a late veneer. This approach results in a maximum core carbon content of $0.09(4)-0.20(10) \mathrm{wt} \%$, consistent with prior estimates based on volatile depletions [7], and corresponds to a bulk Earth with 370(150)-740(370) ppm carbon (78(12)-89(7)\% carbon in the core). For a bulk Earth with $\sim 3000$ ppm sulfur [8], the bulk $\mathrm{C} / \mathrm{S}$ ratio is $0.12(5)-0.25(11)$, most consistent with delivery from carbonaceous chondrite-like precursors.

However, accretion of a late veneer is likely [e.g., 9]. We will present results from core formation models that produce $<120$ ppm mantle carbon to constrain what fraction may have been delivered in a late veneer, and discuss implications for the carbon contents of the core and bulk Earth.

[1] Fischer et al. (2020), PNAS 117, 8743-8749.

[2] Chi et al. (2014), GCA 139, 447-471.

[3] Dasgupta et al. (2013), GCA 102, 191-212.

[4] Grewal et al. (2019), Sci. Adv. 5, eaau3669.

[5] Malavergne et al. (2019), Icarus 321, 473-485.

[6] McDonough \& Sun (1995), Chem. Geol. 120, 223-253.

[7] McDonough (2003), Treatise on Geochemistry vol. 2, 547568.

[8] Suer et al. (2017), EPSL 469, 84-97.

[9] Walker (2009), Chemie der Erde 69, 101-125.
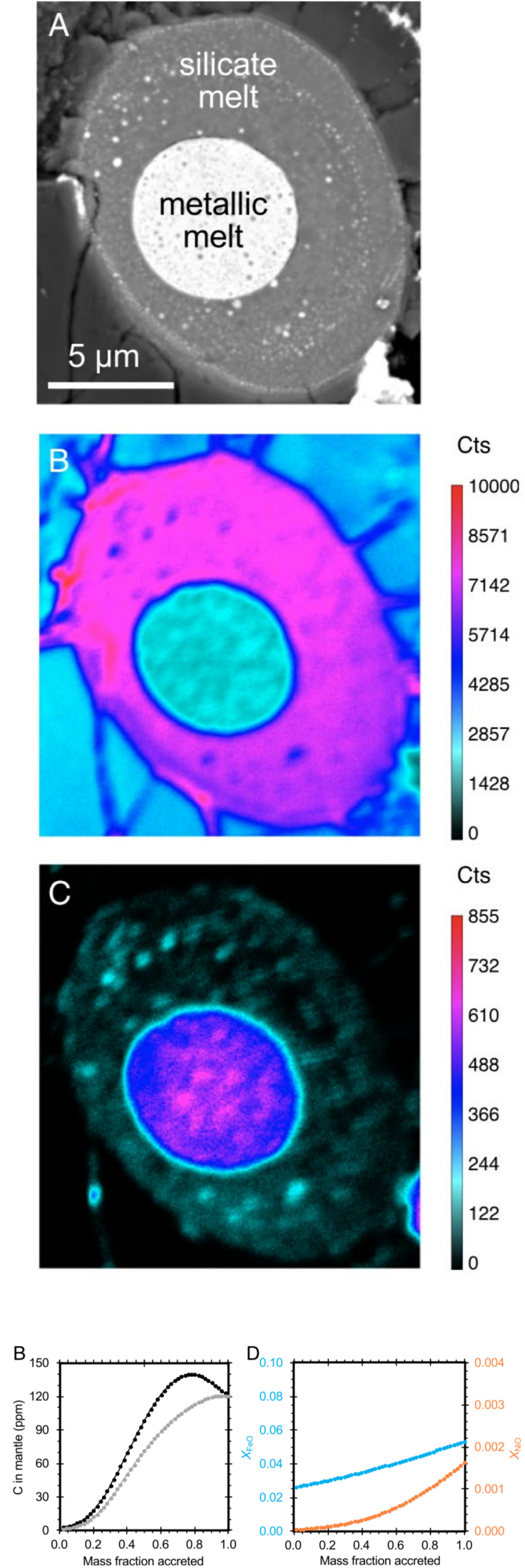